\title{
Stability of Soybean Genotypes and Their Classification into Relative Maturity Groups in Brazil
}

\author{
José Elzevir Cavassim $^{1 *}$, João Carlos Bespalhok Filho ${ }^{1}$, Luis Fernando Alliprandini ${ }^{1}$, \\ Ricardo Augusto de Oliveira ${ }^{1}$, Edelclaiton Daros ${ }^{1}$, Edson Perez Guerra ${ }^{2}$ \\ ${ }^{1}$ Department of Plant Science and Crop Protection, Federal University of Parana, Curitiba, Brazil; ${ }^{2}$ State University of Center-West \\ (Unicentro), Guarapuava, Brazil. \\ Email: ${ }^{*}$ cavassim@hotmail.com
}

Received September $5^{\text {th }}, 2013$; revised October $5^{\text {th }}, 2013$; accepted October $21^{\text {st }}, 2013$

Copyright (C) 2013 José Elzevir Cavassim et al. This is an open access article distributed under the Creative Commons Attribution License, which permits unrestricted use, distribution, and reproduction in any medium, provided the original work is properly cited.

\begin{abstract}
The stability of soybean genotypes is very important in breeding programs for not only the evaluation, selection, and production of cultivars but also the establishment of parameters required for the classification of genotypes into relative maturity groups (RMG). The aim of this study was to define stable genotypes for traits, such as days to flowering, days to maturity, and length of the reproductive period, and to classify them into RMG. For this purpose, 20 commercial soybean cultivars were evaluated in 12 environments distributed in the major producing regions of Brazil. Assessments according to the Eberhart and Russell method and the additive main effects and multiplicative interaction (AMMI) method were effective in the identification of stable genotypes and their classification into RMG. These methods can also be used collectively for this purpose. Our results showed that the AMMI method led to a better interpretation of genotype-environment interactions. Thus, RMG obtained on the basis of stable genotypes represented a good estimate of the relative maturity of soybean crops throughout Brazil.
\end{abstract}

Keywords: Glycine max. (L.) Merrill; Genotype-Environment Interaction; Eberhart and Russell Method; AMMI

\section{Introduction}

The classical approach to describe the maturity of soybeans is given by the classification of genotypes into early, medium, and late phases. In Brazil, breeding companies used a simple categorization based on the maturation cycle of soybean cultivars and classified them as early, medium early, medium, medium late, and late [1]. This method is effective for evaluating crop maturity levels in a local setting, but it is not adequate for describing the relative maturity of soybean crops for a wide range of environments and latitudes in Brazilian areas where these crops are being currently cultivated [2]. This is a simple and effective system from a local standpoint, but as cultivars are cultivated in different regions and environments, the results obtained using this old classification system in such situations may be inaccurate. Moreover, this system does not consider the effects of the time of planting.

In the United States, a rating system has been devel-

${ }^{*}$ Corresponding author. oped, ranging from Group 00, in the northern region of the country, to Group VIII, in the southern region of the country [3]. The adaptation range of each American maturity group is between 200 and $300 \mathrm{~km}$, following a north-south axis in the territory [4].

Alliprandini et al. [2] conducted the first study on RMG in Brazil. Using a system similar to the one employed in the United States, they presented results that allowed the classification of soybean genotypes into RMG throughout the country. After the approval of the Cultivar Protection Law in Brazil [5], several private companies have released soybean cultivars in the market, especially genetically modified glyphosate-resistant cultivars. At present, these resistant cultivars account for approximately $88.8 \%$ of the total area cultivated with soybeans in Brazil [6].

The standardization of cultivar witnesses is essential for the RMG classification of soybean genotypes to be effective. Moreover, these standards are required for the registration and protection of soybean cultivars in Brazil and need to be used jointly by agricultural improvement 
companies [5].

The genotype-environment interaction (GE) is defined as the change in the relative performance of genotypes due to environmental differences. In understanding the effects of the genotype-environment interaction, the adaptability and stability of genotypes provide a valuable tool in the study of relative maturity groups (RMG), since the adaptation of a cultivar is intrinsically correlated with periods of growth, reproduction, and maturation. This correlation depends on the planting season because these genotypes are highly affected by the photoperiod [7].

There are many proposed methods for stability evaluation, and the best known is the one proposed by Eberhart and Russell (ER) [8]. This method is based on simple linear regression analyses. In this method, a genotype is considered stable when the regression coefficient is equal to 1 and the variance of regression deviation is equal to 0 , and additionally when this genotype shows a high average yield. This regression technique has been useful in many cases. The main advantages of this method are interpretability, simplicity, and ability to reduce complex interactions to an ordered set of linear responses. A more recent application method, which also allows inferences of this nature, is additive main effects and multiplicative interaction (AMMI) analysis. This method combines statistical techniques, such as analysis of variance and principal component analysis, to adjust the main effects (genotype and environment) and GE interaction effects, respectively $[9,10]$. The AMMI method can help in the identification of highly productive and largely adapted genotypes for performing agronomical zoning, thereby serving to provide regionalized recommendations and to allow the selection of test sites [11]. According to Zobel et al. [10], some advantages of this method include a more detailed analysis of GE interactions; selection of genotypes, capitalizing on positive interactions with their environments; more accurate estimates of genotypic responses; and easy graphical interpretation of results using biplots (simultaneous graphical representation of genotypes and environments).

Cucolotto et al. [12] found that the AMMI method was effective in explaining the environments and the stability of soybean cultivars. By employing different populations in the $\mathrm{F}_{2}$ generation, Maia et al. [13] determined high stability of the soybean cultivars using the AMMI method. Silva and Duarte [14] used soybean cultures to determine stability parameters using different methods and concluded that the results obtained using the ER and AMMI methods had a low correlation. Therefore, these methods should be used in conjunction for classification purposes.

The aim of this study was to identify stable soybean genotypes using stability methodologies and classify them into their RGM, thus obtaining relative maturity values for any soybean line and cultivar developed through genetic improvement programs in Brazil.

\section{Material and Methods}

We evaluated 20 soybean cultivars, which had been genetically modified for resistance to glyphosate by soybean genetic improvement companies in Brazil, with different attributes of maturity, presence or absence of a long juvenile period, and different growth types (determinate, semi-determinate, and indeterminate) (Table 1). The experiments were conducted at different locations in Brazil, ranging from southern to northern Brazil, during the agricultural years of 2008/2009 and 2009/2010 in order to evaluate traits such as flowering behavior and genotype maturity (Table 1).

For the preparation of the experimental areas, previous desiccation and fertilization were performed. Sowing was performed using a no-tillage system, preferably in the first 2 weeks of November in order to reduce the effects of photoperiodism, and an experimental seeder. Phytosanitary controls were performed in all plots. Each $5.0-\mathrm{m}^{2}$ plot consisted of four $5.0-\mathrm{m}$-long rows, with a spacing of 0.5 meter, and two external lines, which were considered as external boundaries.

The experimental design was a randomized block with two replications per experiment. The following evaluations were performed on each plot: number of days until the stage $\mathrm{R}_{2}$ (NDF) when $50 \%$ of the plants in each plot had at least one open flower and number of days to maturity (NDM) counted from sowing to maturation, considering the stage $\mathrm{R}_{8}$ with at least $95 \%$ of mature pods [15]. Lastly, the number of days for the reproductive period (NDRP) was defined as the difference between NDF and NDM, i.e., the period from flowering to full maturity. After data acquisition, we performed a combined analysis of variance by considering the effects of genotypes, environments, and GE interactions as random parameters and the effect of the year of test as a fixed parameter.

Stability analyses were performed according to the ER method [8] using the program GENES [16] and AMMI analysis [10] using SAS software [17]. After obtaining the scores for AMMI analysis, AMMI stability values (ASV) were calculated using the methodology of [18], as described below:

$$
\mathrm{ASV}_{\mathrm{i}}=\sqrt{\left[\frac{\text { SS IPCA1 }}{\text { SS IPCA2 IPCA1 })]^{2}+(\text { IPCA2 })^{2}}\right.}
$$

where SS IPCA1 and SS IPCA2 are the sums of squares of the AMMI analysis for the first and second axes, respectively, and IPCA1 an IPCA2 are the respective PCA scores. Genotypes considered stable are those with lower values of ASV. 
Based on the results of stability analyses, genotypes considered stable were defined and were used as a reference for determining regression values for the maturity parameters. Using the fitting equation, RMG of the remaining genotypes were established according to the method of Alliprandini et al. [2]. Subsequently, the relative maturity of each genotype was compared with that reported previously [19].

\section{Results and Discussion}

\subsection{Variance Analysis}

The experiments were conducted in various environments, representing the main regions of soybean cultivation in Brazil (Table 1). According to the pooled analysis, low coefficients of variation were obtained for the traits evaluated $(2.3 \%$ for NDF, $1.1 \%$ for NDM, and $3.3 \%$ for NDRP), indicating good precision in establishing and conducting the experiments, as reported by Carvalho et al. [20]. The largest variances for all traits were due to the effects of location (Table 2). The estimates for average heritability were above $90 \%$. Interaction effects were observed in all situations, especially in the year-location interaction, highlighting the major differences between the sites tested. However, the year of test had no effect on any of the traits studied, indicating that the evaluated years produced no significant differences in these traits of the genotypes tested. It had been reported that the west and southwest regions in the state of Paraná, taken in isolation, had less rain in 2008 [21] compared to other locations and years, thus influencing the genotypes allocated in this region to some extent. This conclusion regarding the influence of the environmental conditions on genotypes was drawn by assessing the flowering and ripening periods. Significant differences related to the year-location interaction are due in part to the great variability of the environments tested, from southern to northern Brazil, indicating that, as a whole, years and locations are distinct environmental parameters and should both be considered for the correct evaluation of flowering traits.

The effects of different genotypes were also significant for the traits evaluated, and greater variability was observed for NDM (Table 2). This range of variation had also been verified by Alliprandini et al. [2], making it possible to classify genotypes into distinct RMG, ranging from 5 to 9 . The effects of the genotype-location interaction were also significant for all three traits evaluated, but with lower variability compared to the main effects. This indicates that although this interaction exists, because of regionalized latitude and altitude adaptations, this effect has little influence on the evaluation of genotypes for the traits evaluated (Table 2). Alliprandini et al. [2] reported that the GE interaction was weak for all traits, suggesting that the classification of genotypes into RMG can be performed effectively when considering environments representative of the regions where one wants to produce and commercialize a cultivar. The smaller interaction values are related to the interaction effects of the genotype-year interaction, suggesting that if an array of experiments representative of the cultivation sites is installed, the number of years for the evaluation of cultivars can be reduced. Another important aspect to be noted is the larger magnitude of the GE interaction than the genotype-year interaction. According to Cruz [16], these interactions require a detailed study of the behavior of cultivars and the environment by plant breeders through analysis of stability and adaptability. It is essential to determine the most stable genotypes with greater predictability because they will be the benchmarks for the calculation of maturity [2].

\subsection{ER Analysis}

Flowering (NDF) and maturity (NDM) data for the crops showed the expected average values when the crops were cultivated in their areas of adaptation, since the genotypes showed a predictable response to the environments tested, as can be seen by the values of $\beta$ and $\mathrm{R}^{2}$ (Table 3). The cultivars mostly showed $\mathrm{R}^{2}$ values above $90 \%$, indicating that the regression equation was well adjusted. However, we observed that cultivars having a long juvenile period, because of breeding programs conducted in the northern Brazil, tend to increase their flowering periods when grown in the southern region of the country. Similarly, a cultivar developed in the southern region, which hasn't juvenile traits, tends to accelerate their flowering and maturation cycles when grown in low latitudes [4]. Allied to this is the effect of temperature because as we move the crop to the north and places of lower altitudes, the temperature ranges become higher, particularly after sowing. However, the effects of different latitudes on genotypes is not clearly defined, considering that in northern cultivars, the long juvenile period favors a higher initial growth before flowering, causing prolonged cultivar cycles when sown in the southern region [22].

Regarding the stability of cultivars, deviation from the regression for NDF demonstrated that only the cultivar CD219RR showed lower values that were not significant, thus indicating good stability. As shown in Table 3, deviation values were all highly significant for NDM according to the ER method. Thus, all genotypes showed behavioral differences in maturity, and therefore were not considered stable by the ER method. One alternative would be to consider the smaller deviation values combined with $\beta$ values, but this alternative was not considered. 
Table 1. Description and evaluation of local soybean cultivars in 2008/2009 and 2009/2010 seasons, including their respective RMG, types of growth, and the presence of a long juvenile period (LJP).

\begin{tabular}{|c|c|c|c|c|}
\hline \multicolumn{2}{|c|}{ Crops } & \multirow[t]{2}{*}{ Location } & \multirow[t]{2}{*}{ Elevation (m) } & \multirow[t]{2}{*}{ Latitude } \\
\hline $08-09$ & $09-10$ & & & \\
\hline 1 & 13 & Cascavel-PR & 781 & $25^{\circ} 05^{\prime} \mathrm{S}$ \\
\hline 2 & 14 & Cruz Alta, RS & 452 & $28^{\circ} 60^{\prime} \mathrm{S}$ \\
\hline 3 & 15 & Dourados-MS & 450 & $22^{\circ} 20^{\prime} \mathrm{S}$ \\
\hline 4 & 16 & Maracaju-MS & 384 & $21^{\circ} 60^{\prime} \mathrm{S}$ \\
\hline 5 & 17 & Palotina-PR & 333 & $24^{\circ} 30^{\prime} \mathrm{S}$ \\
\hline 6 & 18 & Passo Fundo-RS-Loc1 & 687 & $28^{\circ} 30^{\prime} \mathrm{S}$ \\
\hline 7 & 19 & Passo Fundo-RS-Loc2 & 660 & $28^{\circ} 45^{\prime} \mathrm{S}$ \\
\hline 8 & 20 & Balsas-MA & 245 & $7^{\circ} 05^{\prime} \mathrm{S}$ \\
\hline 9 & 21 & Cristalina-GO & 1189 & $16^{\circ} 80^{\prime} \mathrm{S}$ \\
\hline 10 & 22 & Morrinhos-GO & 850 & $17^{\circ} 95^{\prime} \mathrm{S}$ \\
\hline 11 & 23 & Rio Verde-GO & 715 & $17^{\circ} 80^{\prime} \mathrm{S}$ \\
\hline 12 & 24 & São G. Oeste-MS & 650 & $19^{\circ} 40^{\prime} \mathrm{S}$ \\
\hline \multicolumn{2}{|c|}{ Genotype } & RMG tabulated & Growth & LJP \\
\hline \multicolumn{2}{|c|}{ Roos CaminoRR } & 5.6 & Indeterminate & No \\
\hline \multicolumn{2}{|c|}{ BMX TitanRR } & 5.6 & Indeterminate & No \\
\hline \multicolumn{2}{|c|}{ CD212RR } & 6.3 & Determinate & No \\
\hline \multicolumn{2}{|c|}{ V-MaxRR } & 6.4 & Indeterminate & No \\
\hline \multicolumn{2}{|c|}{ CD214RR } & 6.8 & Determinate & No \\
\hline \multicolumn{2}{|c|}{ FTS CMRR } & 6.7 & Semi-determinate & No \\
\hline \multicolumn{2}{|c|}{ M7211RR } & 7.0 & Indeterminate & Yes \\
\hline \multicolumn{2}{|c|}{ BRS245RR } & 7.5 & Determinate & Yes \\
\hline \multicolumn{2}{|c|}{ NK7074RR } & 7.1 & Determinate & Yes \\
\hline \multicolumn{2}{|c|}{ M7578RR } & 7.2 & Determinate & Yes \\
\hline \multicolumn{2}{|c|}{ Fundacep54RR } & 7.5 & Determinate & No \\
\hline \multicolumn{2}{|c|}{ Fundacep59RR } & 7.6 & Determinate & No \\
\hline \multicolumn{2}{|c|}{ M7908RR } & 7.6 & Determinate & Yes \\
\hline \multicolumn{2}{|c|}{ P98Y11 } & 7.6 & Determinate & Yes \\
\hline \multicolumn{2}{|c|}{ CD219RR } & 8.2 & Determinate & Yes \\
\hline \multicolumn{2}{|c|}{ ValiosaRR } & 8.1 & Determinate & Yes \\
\hline \multicolumn{2}{|c|}{ TMG103RR } & 8.3 & Determinate & Yes \\
\hline \multicolumn{2}{|c|}{ P98Y51 } & 8.6 & Determinate & Yes \\
\hline \multicolumn{2}{|c|}{ P98Y70 } & 8.7 & Determinate & Yes \\
\hline \multicolumn{2}{|c|}{ M9144RR } & 9.2 & Determinate & Yes \\
\hline
\end{tabular}

With respect to NDRP, a difference of 12 days was observed between the lowest value (CD212RR) and the highest value (M9144RR), and the reproductive period showed a response positively correlated with the environments tested, except for the genotypes with larger groups of maturity (P98Y51, P98Y70, and M9144RR). These genotypes showed a lower amplitude in the grain filling period, with smaller $\beta$ and $\mathrm{R}^{2}$ values (Table 3). George et al. [23] used soybean cultivars from different maturity groups and showed that the maturity of soybean was delayed by the decrease in temperature in high-altitude environments and, in each environment, the length of the vegetative phase increased with increasing maturity, probably because of the photoperiod.

Among the most stable cultivars, deviations were highly variable for NDRP. Thus, besides considering the smaller deviation values, $\mathrm{R}^{2}$ values were also taken into account. The cultivars considered stable, given the 
Table 2. Summary of analysis of variance for the traits number of days to flowering (NDF), number of days to maturity (NDM), and number of days for the reproductive period (NDRP).

\begin{tabular}{|c|c|c|c|c|}
\hline \multirow{2}{*}{ SV } & \multirow{2}{*}{ DF } & \multicolumn{3}{|c|}{ MS } \\
\hline & & $\mathrm{NDF}$ & NDM & NDRP \\
\hline$(\mathrm{B} / \mathrm{L}) / \mathbf{Y}$ & 24 & 2.9 & 2.9 & 4.5 \\
\hline Gen (G) & 19 & $2695.2^{* *}$ & $4709.1^{* *}$ & $457.8^{* *}$ \\
\hline Years (Y) & 1 & $8437.2^{\mathrm{ns}}$ & $1144.0^{\mathrm{ns}}$ & $3241.3^{\text {ns }}$ \\
\hline Location (L) & 11 & $11471.0^{* *}$ & $14999.1^{* *}$ & $1877.1^{* *}$ \\
\hline GXY & 19 & $65.2^{* *}$ & $59.9^{* *}$ & $49.1^{* *}$ \\
\hline GxL & 209 & $33.8^{* *}$ & $33.5^{* *}$ & $37.9^{* *}$ \\
\hline YxL & 11 & $1828.3^{* *}$ & $1750.5^{* *}$ & $1106.3^{* *}$ \\
\hline GxYxL & 209 & $21.0^{* *}$ & $22.9^{* *}$ & $23.4^{* *}$ \\
\hline Residual & 456 & 1.5 & 1.7 & 5.5 \\
\hline Average (days) & & 52.0 & 122.7 & 70.4 \\
\hline Heritability (\%) & & 98.7 & 99.2 & 91.7 \\
\hline CV (\%) & & 2.3 & 1.1 & 3.3 \\
\hline
\end{tabular}

${ }^{\text {ns: }}$ : not significant $(\mathrm{p}>0.01) ;{ }^{* *}$ : significant $(\mathrm{p}<0.01)$; SV: sources of variation; DF: degrees of freedom; MS: mean square; and CV: coefficient of variation.

Table 3. Estimates of parameters of adaptability and stability of the traits number of days to flowering (NDF), number of days to maturity (NDM), and number of days for the reproductive period (NDRP) determined using the method of Eberhart and Russell [8] for crops grown in 24 environments in 2008/2009 and 2009/2010 seasons.

\begin{tabular}{|c|c|c|c|c|c|c|c|c|c|c|c|c|}
\hline \multirow{2}{*}{ Genotype } & \multicolumn{4}{|c|}{ NDF } & \multicolumn{4}{|c|}{ NDM } & \multicolumn{4}{|c|}{ NDRP } \\
\hline & Mean & $\boldsymbol{\beta} \mathbf{1}_{\mathrm{i}}$ & $\sigma_{\mathrm{di}}^{2}$ & $\mathrm{R}^{2}(\%)$ & Mean & $\beta 1_{i}$ & $\sigma_{\mathrm{di}}^{2}$ & $\mathbf{R}^{2}(\%)$ & Mean & $\boldsymbol{\beta} \mathbf{1}_{\mathrm{i}}$ & $\sigma_{\mathrm{di}}^{2}$ & $\mathbf{R}^{2}(\%)$ \\
\hline Roos CaminoRR & 39.0 & 0.87 & $12.52^{* *}$ & 89.9 & 106.4 & 0.86 & $4.20^{* *}$ & 96.7 & 67.2 & $1.16^{* *}$ & $7.19^{* *}$ & 77.7 \\
\hline BMX TitanRR & 40.0 & 0.86 & $8.38^{* *}$ & 92.7 & 108.1 & 0.83 & $1.94^{* *}$ & 98.0 & 67.9 & $1.10^{* *}$ & $6.06^{* *}$ & 77.9 \\
\hline CD212RR & 44.7 & $0.98^{* * *}$ & $6.81^{* *}$ & 95.8 & 111.4 & 1.13 & $5.66^{* *}$ & 97.5 & 66.3 & 1.35 & $6.59^{* *}$ & 83.4 \\
\hline V-MaxRR & 42.9 & $1.02^{* *}$ & $2.51^{* *}$ & 98.1 & 113.3 & $1.00^{* *}$ & $3.39^{* *}$ & 98.0 & 70.2 & 1.26 & $1.38^{\mathrm{ns}}$ & 90.7 \\
\hline CD214RR & 46.1 & 1.21 & $4.56^{* *}$ & 97.7 & 116.0 & 1.19 & $1.79^{* *}$ & 99.1 & 69.7 & 1.37 & $1.08^{\mathrm{ns}}$ & 92.6 \\
\hline FTS CMRR & 48.6 & 0.92 & $2.80^{* *}$ & 97.4 & 116.7 & $1.04^{*}$ & $1.94^{* *}$ & 98.7 & 67.6 & 1.23 & $2.32^{\mathrm{ns}}$ & 88.5 \\
\hline M7211RR & 47.9 & $1.04^{*}$ & $3.46^{* *}$ & 97.6 & 118.2 & 1.08 & $4.10^{* *}$ & 97.9 & 70.2 & 1.43 & $4.76^{* *}$ & 87.4 \\
\hline BRS245RR & 51.2 & 0.94 & $10.17^{* *}$ & 92.6 & 118.5 & $0.98^{* *}$ & $9.52^{* *}$ & 95.0 & 67.0 & $0.92^{* *}$ & $2.07^{\mathrm{ns}}$ & 81.7 \\
\hline NK7074RR & 50.8 & 0.94 & $15.86^{* *}$ & 89.3 & 119.3 & 1.11 & $2.78^{* *}$ & 98.5 & 67.4 & $1.01^{* *}$ & $7.69^{* *}$ & 71.4 \\
\hline M7578RR & 51.6 & 1.06 & $20.28^{* *}$ & 89.3 & 121.1 & 1.11 & $3.92^{* *}$ & 98,1 & 68.8 & $0.84^{* *}$ & $4.04^{* *}$ & 73.0 \\
\hline Fundacep54RR & 49.7 & 1.23 & $2.28^{* *}$ & 98.7 & 122.7 & 1.12 & $4.74^{* *}$ & 97.8 & 72.6 & $1.01^{* *}$ & $6.35^{* *}$ & 74.2 \\
\hline Fundacep59RR & 54.5 & 0.89 & $2.16^{* *}$ & 97.7 & 122.9 & $0.98^{* *}$ & $2.78^{* *}$ & 98.1 & 68.1 & $0.96^{* *}$ & $4.47^{* *}$ & 76.6 \\
\hline M7908RR & 52.9 & 0.94 & $0.74^{*}$ & 98.9 & 123.6 & 1.04 & $4.08^{* *}$ & 97.8 & 70.2 & $1.05^{* *}$ & $6.91^{* *}$ & 74.7 \\
\hline P98Y11 & 52.5 & $1.04^{*}$ & $2.52^{* *}$ & 98.1 & 123.9 & $1.02^{* *}$ & $1.40^{* *}$ & 98.9 & 71.2 & $0.94^{* *}$ & $1.77^{\mathrm{ns}}$ & 95.8 \\
\hline CD219RR & 57.7 & 0.89 & $0.29^{\mathrm{ns}}$ & 99.1 & 129.5 & 0.94 & $8.15^{* *}$ & 95.2 & 71.6 & 0.81 & $5.62^{* *}$ & 67.0 \\
\hline ValiosaRR & 57.4 & 1.03 & $1.57^{* *}$ & 98.6 & 133.0 & $0.99^{* *}$ & $6.90^{* *}$ & 96.3 & 75.2 & $0.88^{* *}$ & $1.67^{\mathrm{ns}}$ & 81.9 \\
\hline TMG103RR & 62.9 & 1.07 & $7.68^{* *}$ & 95.5 & 134.4 & $0.96^{*}$ & $9.28^{* *}$ & 94.9 & 71.1 & $0.98^{* *}$ & $8.42^{* *}$ & 68.8 \\
\hline P98Y51 & 62.6 & 1.15 & $3.59^{* *}$ & 97.9 & 136.0 & $0.98^{* *}$ & $17.58^{* *}$ & 91.5 & 72.9 & 0.54 & $18.28^{* *}$ & 26.4 \\
\hline P98Y70 & 62.8 & 0.93 & $9.75^{* *}$ & 92.8 & 136.8 & 0.76 & $7.16^{* *}$ & 93.7 & 73.9 & 0.53 & $9.45^{* *}$ & 37.0 \\
\hline M9144RR & 63.4 & $0.99^{* *}$ & $9.00^{* *}$ & 94.1 & 141.9 & 0.86 & $8.60^{* *}$ & 94.1 & 78.2 & 0.64 & $8.11^{* *}$ & 49.3 \\
\hline
\end{tabular}

$\beta 1_{\mathrm{i}}$ : linear response of genotype I to environmental variation; $\sigma_{\mathrm{di}}^{2}$ : deviation from the regression; $\mathrm{R}^{2}$ : coefficient of determination. ${ }^{\text {ns }}$ : not significant ( $\left.\mathrm{p}>0.05\right)$; ${ }^{*}$ and ${ }^{* *}(\mathrm{p}<0.05)$ and $(\mathrm{p}<0.01)$, respectively. 
RR. All of them showed high $\mathrm{R}^{2}$ values. Finally, five cultivars were considered stable by the ER method. However, cultivars considered stable for NDF were not stable for NDM and NDRP. The fact that the evaluated cultivars had determinate, semi-determinate, or indeterminate types of growth had no influence on the results, considering that all of them were among the most stable.

\subsection{AMMI Analysis}

According to AMMI analysis, the first genotypic component for flowering represented $28.6 \%$ of the sum of squares of the interaction and the second component represented $23.5 \%$ (Table 4 ). Therefore, with only two components, it was possible to explain the GE interaction for flowering in 51.1\%.For NDM, the AMMI2 biplot, which shows the interaction effects of IPCA1 versus IPCA2, indicates that the percentage for IPCA1 and IPCA 2 was $37.1 \%$ and $13.9 \%$, respectively, totaling $51 \%$, with two components (Figure 1). In this graphical representation, genotypes located close to the origin are considered the most stable, which means that they contributed little to the GE interaction. Duarte and Vencovsky [24] have defined that genotypes are evaluated on the basis of their respective adaptive amplitudes and are stable and adapted to the test environments. Although the sum of cumulative percentage is equivalent to that of flowering, the first genotypic component for maturation was more significant and represented most of the interaction

Table 4. Eigenvalues (E) and cumulative percentages for the traits number of days to flowering (NDF), number of days to maturity (NDM), and number of days to the reproductive period (NDRP) determined using the AMMI method. Values for the two main components of interaction (IPCA1 and IPCA2) and ASV values for maturation for genotypes of crops grown in 24 environments in 2008/2009 and 2009/2010 seasons.

\begin{tabular}{|c|c|c|c|c|c|c|c|}
\hline \multirow{2}{*}{ PC } & \multicolumn{2}{|c|}{ NDF } & \multicolumn{2}{|c|}{ NDM } & \multicolumn{2}{|c|}{ NDRP } & \\
\hline & $\mathbf{E}^{*}$ & $\%$ Ac. & $\mathbf{E}^{*}$ & $\%$ Ac. & $\mathbf{E}^{*}$ & $\%$ Ac. & \\
\hline 1 & 1819.91 & 28.63 & 2402.53 & 37.10 & 2202.00 & 32.04 & \\
\hline 2 & 1494.99 & 52.15 & 900.32 & 51.00 & 1193.12 & 49.39 & \\
\hline 3 & 1293.34 & 72.50 & 828.92 & 63.80 & 603.33 & 58.17 & \\
\hline 4 & 624.02 & 82.31 & 595.05 & 72.98 & 567.89 & 66.43 & \\
\hline 5 & 344.25 & 87.73 & 469.05 & 80.23 & 512.62 & 73.89 & \\
\hline Genotype & IPCA1 & IPCA2 & IPCA1 & IPCA2 & IPCA1 & IPCA2 & ASV \\
\hline P98Y11 & -0.1 & 0.2 & 0.0 & -0.1 & 0.2 & 0.1 & 0.1 \\
\hline Fundacep59RR & 0.4 & 1.0 & 0.0 & -0.7 & -0.9 & 0.7 & 0.7 \\
\hline M7908RR & -0.1 & 0.8 & -0.2 & -0.8 & -0.9 & 2.2 & 1.0 \\
\hline Roos CaminoRR & 2.3 & -1.7 & -0.6 & 0.3 & -1.0 & -2.1 & 1.7 \\
\hline BMX TitanRR & 1.8 & -1.5 & -0.7 & -0.4 & -1.1 & -1.8 & 1.9 \\
\hline CD219RR & 0.5 & 0.5 & 1.0 & -0.6 & 0.0 & 0.7 & 2.8 \\
\hline V-MaxRR & 1.0 & -1.3 & -1.1 & 0.2 & -0.5 & -1.9 & 2.9 \\
\hline Fundacep54RR & -0.1 & -0.4 & -1.1 & -0.4 & -0.1 & -0.2 & 3.0 \\
\hline FTS CMRR & 6.3 & 0.0 & -1.1 & 0.6 & -1.4 & -0.3 & 3.1 \\
\hline M7211RR & 0.7 & -0.6 & -1.3 & 0.4 & -1.6 & -1.0 & 3.7 \\
\hline NK7074RR & -3.7 & -0.8 & -1.5 & 0.0 & -1.1 & 2.6 & 4.1 \\
\hline ValiosaRR & -0.1 & 0.6 & 1.6 & -0.6 & 1.2 & -0.1 & 4.4 \\
\hline M7578RR & -3.8 & -1.2 & -1.6 & -0.4 & -0.8 & 1.9 & 4.4 \\
\hline CD214RR & 0.5 & -2.0 & -1.8 & 0.1 & -0.5 & -1.5 & 4.9 \\
\hline BRS245RR & 1.2 & 3.1 & 6.9 & 4.7 & 0.1 & 0.8 & 5.3 \\
\hline CD212RR & 0.4 & -1.8 & -2.0 & -0.8 & -1.7 & 0.0 & 5.6 \\
\hline M9144RR & -0.2 & 2.1 & 2.3 & 0.7 & 2.2 & 0.7 & 6.2 \\
\hline P98Y51 & -0.4 & 0.6 & 2.3 & -1.1 & 3.4 & 0.0 & 6.4 \\
\hline P98Y70 & -0.2 & 1.8 & 2.5 & 0.2 & 2.4 & 0.0 & 6.7 \\
\hline TMG103RR & -0.4 & 0.4 & 2.6 & -1.3 & 2.6 & -1.1 & 7.2 \\
\hline
\end{tabular}

*Only the first five principal components of decomposition are shown. 


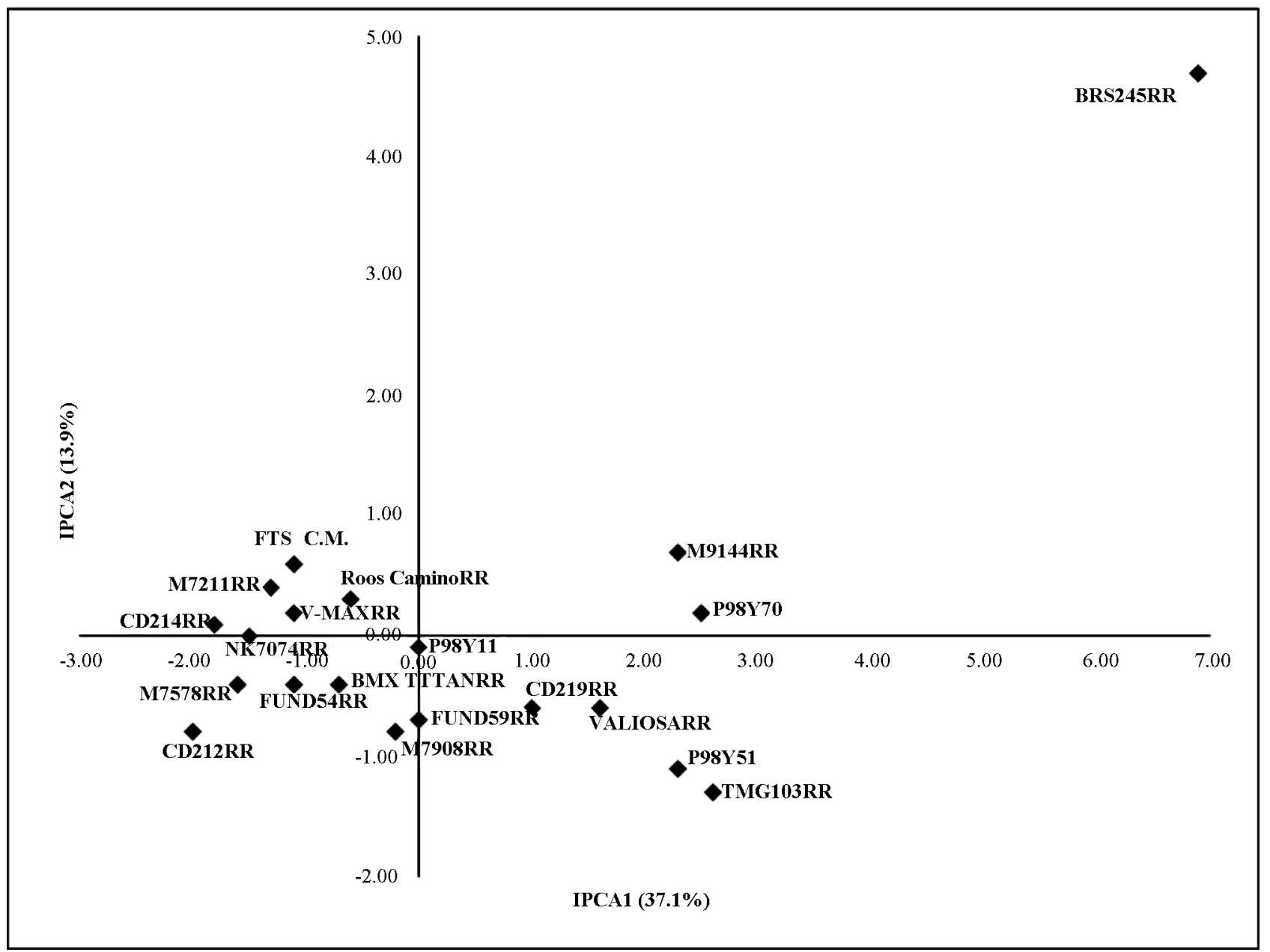

Figure 1. AMMI2 biplotwith the two main components of interaction (IPCA1 and IPCA2) corresponding to the maturity of 20 genotypes.

(37.1\%). The scores can show us how genotypes and environments interact. Thus, components with even signs interact positively, showing adaptive synergism, whereas components with odd signs suggest a negative interaction [24]. For NDRP, the components IPCA1 and IPCA2 accounted for $49.3 \%$ of the interaction (Table 4). Thus, to establish stable genotypes among the three traits, it was decided to use as a reference only NDM, because the first term has the largest representation.

For all maturity groups to be represented in order to obtain the regression, the cultivar M9144RR showed the best performance, given its lowest ASV values, among all late genotypes. According to Oliveira et al. [25], maturation and late seasonal diseases are important components in the GE interaction. This can be observed when cultivating late genotypes with long juvenile periods in areas of high latitude, as in the southern region. These cultivars remain longer in the field, making them more vulnerable not only to environmental influences but also to attacks of pests and pathogens, precluding a more accurate assessment of maturity. Thus, although a maturation phase can be determined for these genotypes, it is regarded as late and unstable.

By the definition of stable cultivars, in addition to the cultivar M9144RR, cultivars P98Y11, Fundacep 59RR, M7908RR, Roos Camino RR, and BMX TITAN RR were identified employing the AMMI method and the lowest ASV values for maturation (NDM) as reference. Among the five stable cultivars identified by the ER method, only one was also identified using the AMMI method. Using the AMMI method, we selected six cultivars as stable, two of which were indeterminate, whereas late cultivars tended to have higher ASV values, and therefore were more unstable. In general, even considering small deviations from the expected values, the method was effective in calculating RMG. Similar results were obtained by Alliprandini et al. [2] using the ER method. The AMMI method tries to adjust the model more accurately by decomposing the sum of squares of the interaction, making it possible to identify genotype 
stability with biplot graphs. Benin et al. [26] used biplot techniques to evaluate the agronomic performance of wheat, allowing inferences to be made about its genotypes.

\subsection{RMG Classification}

Using average maturity values from the tests and more stable cultivars according to the methods of stability analysis used in this study, RMG were calculated using linear regression analysis, which showed high $\mathrm{R}^{2}$ values (Table 5). The RMG values obtained were compared with those previously reported and disclosed by soybean research companies [18]. The values are consistent with the expected values, starting with the lower ones, with 5.6 and reaching approximately 8.1. The late genotypes had RMG values $(8.7$ - 9.1) greater than the expected values. Both the ER and AMMI methods showed similar classification results, although AMMI tended to be more selective for late genotypes. Taken together, we believe that further studies including the assessment of more genotypes and test sites will be of great importance, as it allows better use of the specific potential of each genotype and the adequate placement of the genotype in their areas of adaptation. Another opportunity would be to establish separate trials for the southern and northern regions, to study new methods of stability for a better definition and selection of the most stable genotypes, and toimprove the classification of maturity groups.

\section{Conclusion}

According to the results, the AMMI and ER methods were effective in the identification of stable genotypes and can be used in combination for their classification into RMG. Both methodologies were classified as expected, mainly up to the group 8.1, although later cultivars had their RMG values established above the expected values. We conclude that the AMMI method leads

Table 5. Values of relative maturity groups (RMG) established by regression, using the genotypes classified as stable according to the method of Eberhart and Russell [8] and AMMI analysis [10], and those established according to the method of Alliprandini et al. [19].

\begin{tabular}{|c|c|c|c|c|}
\hline \multirow{2}{*}{ Genotype } & \multirow{2}{*}{ Average (days) } & \multicolumn{2}{|c|}{ Calculated RMG Calculated } & \multirow{2}{*}{ RMG Tabulated } \\
\hline & & ER & AMMI & \\
\hline ROOS CaminoRR & 106.4 & 5.6 & 5.6 & 5.6 \\
\hline BMX TITAN RR & 108.1 & 5.8 & 5.8 & 5.6 \\
\hline CD212RR & 111.4 & 6.2 & 62 & 6.3 \\
\hline V-MaxRR & 113.3 & 6.4 & 6.4 & 6.4 \\
\hline CD214RR & 116.0 & 6.7 & 6.7 & 6.8 \\
\hline FTS C.MOURÃO RR & 116.7 & 6.8 & 6.7 & 6.7 \\
\hline M7211RR & 118.2 & 7.0 & 6.9 & 7.0 \\
\hline BRS245 RR & 118.5 & 7.0 & 6.9 & 7.5 \\
\hline NK7074 & 119.3 & 7.1 & 7.2 & 7.1 \\
\hline M7578RR & 121.1 & 7.3 & 7.2 & 7.2 \\
\hline FUNDACEP54RR & 122.7 & 7.4 & 7.4 & 7.5 \\
\hline FUNDACEP59RR & 122.9 & 7.5 & 7.4 & 7.6 \\
\hline M7908RR & 123.6 & 7.6 & 7.5 & 7.6 \\
\hline P98Y11 & 123.9 & 7.6 & 7.5 & 7.6 \\
\hline CD219RR & 129.5 & 8.2 & 8.1 & 8.2 \\
\hline VALUABLE RR & 133.0 & 8.6 & 8.5 & 8.1 \\
\hline TMG103RR & 134.4 & 8.7 & 8.6 & 8.3 \\
\hline P98Y51 & 136.0 & 8.9 & 8.8 & 8.6 \\
\hline P98Y70 & 136.8 & 9.0 & 8.9 & 8.7 \\
\hline M9144RR & 141.9 & 9.6 & 9.4 & 9.2 \\
\hline
\end{tabular}

ER: $y=0.1107 x-6.1373 R^{2}=0.9926$; AMMI: $y=0.1063 x-5.679 R^{2}=0.9823$. 
to a better interpretation of the GE interactions. We suggest furthering these studies by employing other methodologies and by separating the southern and northern environments to determine the best fit for RMG.

\section{Acknowledgements}

We thank the following researchers and institutions for their valuable contribution to the study: Leonardo Oliveira and Eduardo Lambert (MONSOY), Marco Rott (COODETEC), Andreomar Kurek (Syngenta), Cleiton Steckling (FUNDACEP), Carlos Pitol (FUNDAÇÃO MS), Nizio Giasson and Marcos Matsumoto (DON MARIO), Paulo Bertagnolli and Maria do Rosário Teixeira (EMBRAPA), Anderson Dona (WEHRTEC), and Luis Stabile (SOYTECH).

\section{REFERENCES}

[1] L. F. Alliprandini, J. F. F. Toledo, N. Fonseca Jr., L. A. Almeida and R. A. S. Kiihl, "Effects of GenotypeEnvironment Interaction on Soybean Yield in the Paraná State," Pesquisa Agropecuária Brasileira, Vol. 29, No. 9, 1994, pp. 1433-1444.

[2] L. F. Alliprandini, C. Abatti, P. F. Bertagnolli, J. E. Cavassim, H. L. Gabe, A. Kurek, M. N. Matsumoto, M. A. R. Oliveira, C. Pitol, L. C. Prado and C. Steckling, "Understanding Soybean Maturity Groups in Brazil: Environment, Cultivar Classification, and Stability," Crop Science, Vol. 49, No. 3, 2009, pp. 801-808. http://dx.doi.org/10.2135/cropsci2008.07.0390

[3] L. X. Zhang, S. Kyei-Boahen, J. Zhang, M. H. Zhang, T. B. Freeland, C. E. Watson Jr. and X. M. Liu, "Modifications of Optimum Adaptation Zones for Soybean Maturity Groups in the USA," Crop Management. (Online) http://dx.doi.org/10.1094/CM-2007-0927-01-RS

[4] H. A. Bruns, "A Survey of Factors Involved in Crop Maturity," Agronomy Journal, Vol. 101, No. 1, 2009, pp. 6066. http://dx.doi.org/10.2134/agronj2007.0271R

[5] Brazil, "Ministry of Agriculture, Livestock and Supply. Cultivar Protection in Brazil," MAPA/ACS, Brasília, 2011, p. 202.

[6] Céleres, "Biotechnology Report," Céleres Consulting, Uberlandia, 2012, p. 9.

[7] G. V. Meotti, G. Benin, R. R. Silva, E. Beche and L. B. Munaro, "Sowing Dates and Agronomic Performance of Soybean Cultivars," Pesquisa Agropecuária Brasileira, Vol. 47, No. 1, 2012, pp. 14-21. http://dx.doi.org/10.1590/S0100-204X2012000100003

[8] S. A. Eberhart and W. A. Russell, "Stability Parameters for Comparing Varieties," Crop Science, Vol. 6, No. 1, 1966, pp. 36-40. http://dx.doi.org/10.2135/cropsci1966.0011183X0006000 $\underline{10011 \mathrm{x}}$

[9] R. A. Kempton, "The Use of Biplots in Interpreting Variety by Environment Interactions," Journal of Agricultural Science, Vol. 103, No. 1, 1984, pp. 123-135.
http://dx.doi.org/10.1017/S0021859600043392

[10] R. W. Zobel, M. J. Wright and H. G. Gauch, "Statistical Analysis of a Yield Trial," Agronomy Journal, Vol. 80, No. 3, 1988, pp. 388-393. http://dx.doi.org/10.2134/agronj1988.0002196200800003 $\underline{0002 x}$

[11] H. G. Gauch and R. W. Zobel, "AMMI Analysis of Yield Trials," In: M. S. Kang and H. G. Gauch, Eds., Genotypeby-Environment Interaction, CRC Press, New York, 1996, p. 416.

[12] M. Cucolotto, V. C. Pípolo, D. D. Garbuglio, N. S. Fonseca Jr., D. Destro and M. K. Kamikoga, "Genotype $\times$ Environment Interaction in Soybean: Evaluation through Three Methodologies," Crop Breeding and Applied Biotechnology, Vol. 7, No. 3, 2007, pp. 270-277.

[13] M. C. C. Maia, N. A. Vello, M. M. Rocha, J. B. Pinheiro and N. F. Silva Jr., "Adaptability and Stability of Soybean Experimental Lines Selected for Agronomic Traits and Insect Resistance by Uni-Multivariate Method," Bragantia, Vol. 65, No. 2, 2006, pp. 215-226. http://dx.doi.org/10.1590/S0006-87052006000200004

[14] W. C. J. Silva and J. B. Duarte, "Statistical Methods to Study Phenotypic Adaptability and Stability in Soybean," Pesquisa Agropecuária Brasileira, Vol. 41, No. 1, 2006, pp. 23-30. http://dx.doi.org/10.1590/S0100-204X2006000100004

[15] W. R. Fehr and C. E. Caviness, "Stages of Soybean Development," Special Report 80, Iowa State University, Ames, 1977.

[16] C. D. Cruz, "Genes Program: Windows Version: Application in Genetics and Statistics," Editora UFV, Viçosa, 2001, p. 648.

[17] SAS Institute, "SAS User's Guide," SAS Institute, Cary, 1999.

[18] J. L. Purchase, H. Hatting and C. S. Van Deventer, "Genotype $\times$ Environment Interaction of Winter Wheat in South Africa: II. Stability Analysis of Yield Performance," South African Journal of Plant Soil, Vol. 17, No. 3, 2000, pp. 101-107. http://dx.doi.org/10.1080/02571862.2000.10634878

[19] L. F. Alliprandini, J. E.Cavassim, M. A. R. Oliveira, M. N. Matsumoto, L. C. Prado, C. Pitol, C. Steckling, P. F. Bertagnoli, A. Kurek, M. K. Kamikoga, A. Dona, N. F. Giasson, C. Abatti, G. D. Silveira and C. Takeda, "Classification of Soybean Cultivarsin to Relative Maturity Groups in Brazil, during 2001/2002-2011/2012 Seasons," 7th Congress of Plant Breeding, SBMP, Uberlandia, 2013.

[20] C. G. P. Carvalho, C. A. A. Arias, J. F. F. Toledo, L. A. Almeida, R. A. S. Kiihl and M. F. Oliveira, "Genotypex Environment Interaction on Soybean Production Performance in Paraná," Pesquisa Agropecuária Brasileira, Vol. 37, No. 7, 2002, pp. 989-1000. http://dx.doi.org/10.1590/S0100-204X2002000700013

[21] Simepar, "Condições do Tempo," 2013. http://www.simepar.br/tempo/clima/aviso_verao2009.htm

[22] D. Destro, V. Carpentieri-Pípolo, R. A. S. Kiihl and L. A. Almeida, "Photoperiodic and Genetic Control of the Long 
Juvenile Period in Soybean: A Review," Crop Breeding and Applied Biotechnology, Vol. 1, No. 1, 2001, pp. 7292. http://dx.doi.org/10.13082/1984-7033.v01n01a10

[23] T. George, D. P. Bartholomew and P. W. Singleton, "Effect of Temperature and Maturity Group on Phenology of Field Grown Nodulating and Nonnodulating Soybean Isolines," Biotronics, Vol. 19, 1990, pp. 49-59.

[24] J. B. Duarte and R. Vencovsky, "Genotypex Environment Interaction: An Introduction to AMMI Analysis," Série Monograph Series, Brazilian Society of Genetics, Ribeirao Preto, 1999.
[25] A. B. Oliveira, J. B. Duarte, L. J. Chaves and M. A. Couto, "Environmental and Genotypic Factors Associated with Genotype by Environment Interactions in Soybean," Crop Breeding and Applied Biotechnology, Vol. 6, 2006, pp. 79-86.

[26] G. Benin, C. Pinnow, C. L. Silva, E. S. Pagliosa, E. Beche, E. Bornhofen, L. B. Munaro and R. R. Silva, "Biplot Analysis in the Evaluation of Wheat Cultivarsat Different Levels of Management," Bragantia, Campinas, Vol. 71, No. 1, 2012, pp. 28-36. 